\title{
Intraperitoneal Administration of Nucleoside-Nucleotide Mixture Inhibits Endotoxin-Induced Bacterial Translocation in Protein-Deficient Mice
}

\author{
Andrew A. Adjei, Yoshihide Ohshiro*, Keiko \\ Yamauchi*, Yoko Nakasone*, Katsumasa Shimada*, \\ Masaaki Iwanaga and Shigeru Yamamoto* \\ Department of Bacteriology, Faculty of Medicine and \\ * School of Health Sciences and Research Center of \\ Comprehensive Medicine, University of the Ryukyus, \\ Okinawa 903-01
}

Adjei, A.A., Ohshiro, Y., Yamauchi, K., Nakasone, Y., Shimada, K., Iwanaga, M. and Үамамото, S. Intraperitoneal Administration of NucleosideNucleotide Mixture Inhibits Endotoxin-Induced Bacterial Translocation in ProteinDeficient Mice. Tohoku J. Exp. Med., 1994, 174 (1), 1-10— Nucleosides and nucleotides as a precursor for nucleic acid synthesis may be essential for rapidly growing cells, since intestinal epithelial cells have limited capacity for the de novo purine and pyrimidine synthesis. The present study was undertaken to determine the effect of intraperitoneal administration of nucleoside-nucleotide mixture (NNM) or saline on endotoxin-induced bacterial translocation, ileal histology, and cecal population levels in protein-deficient mice. Intraperitoneal administration of NNM for 14 days was associated with reduced translocation of gram-negative enterics to the mesenteric lymph node and spleen in comparison to saline. Histologically, the extent of the damage to the gut mucosa was greater in the saline group. This was confirmed by the profound diminution of the villous height, crypt depth, and the intestinal wall in the saline treated group as compared to the NNM treated group, suggestive of the efficacy of NNM in improving the gut and epithelial mucosal cells. However, the cecal population levels in both groups were not different. Additionally, the mice in the saline group were more susceptible to the lethal effects of endotoxin as compared to the NNM group suggesting that NNM may be essential for the enhancement of the host defense system. These results suggest that NNM may be used to an advantage to inhibit or reduce the incidence of endotoxin-induced bacterial translocation and improved survival in proteindeficient mice. - nucleoside-nucleotide; endotoxin; mouse; bacterial translocation; protein-deficient

The gut plays a very important role, not only for digestion and absorption of

Received May 12, 1994; revision accepted for publication July 21, 1994.

Address for reprints: Andrew Anthony Adjei, Department of Bacteriology, Faculty of Medicine, University of the Ryukyus, 207 Uehara, Okinawa 903-01, Japan. 
diets, but also as a major local defense barrier that helps prevent bacteria and endotoxin normally contained within the gut from escaping and invading distant organs and tissues. However, under certain experimental and some clinical circumstances, this intestinal barrier function seems to be impaired leading to the translocation of bacteria or endotoxin to the mesenteric lymph nodes (MLN) and systemic tissues (Berg and Garlington 1979). Bacterial translocation from the gut is emerging as an important pathogenic phenomenon and are potential sources of septicemia in immunocompromised hosts (Wilmore et al. 1988; Saadia et al. 1990). Factors that promote the translocation of bacteria from the gut include disruption of the ecologic balance of the normal indigenous microflora, resulting in bacterial overgrowth; impaired host immune defenses; physical disruption of the gut mucosal barrier; trauma; and endotoxemia (Wells et al. 1988).

Protein deficiency is identified as the most common cause of immunosuppression world-wide (Garre et al. 1987). It impairs host antibacterial defenses and is associated with morphologic and functional changes in the gut and in combination with endotoxin promotes bacterial translocation from the gut (Deitch et al. 1987). The gut injury associated with protein deficiency and endotoxemia includes destruction of proliferative crypt cells, decreased villus height and ulceration of the gut epithelium (Deitch et al. 1987). The morbidity, mortality, and costs associated with treatment of the complications of protein deficiency in combination with endotoxemia are substantial, and thus any therapy that would protect the gut from injury would be beneficial. Because protein deficiency are relatively common in hospitalized and immunocompromised patients and may impair antibacterial host defenses and disrupt the normal ecologic balance of the gut microflora; and in combination with endotoxin promote bacterial translocation, we have been interested in the maintenance of the gut integrity and function using specific nutrients or subtrates.

Nucleosides and nucleotides one of the principal fuels used by the gut for growth, maturation, and repair during injury are absent from the commercially available parenteral and enteral nutritional formulas. For this reason, the present study was designed to examine the effect of intraperitoneal (IP) administration of nucleoside-nucleotide mixture (NNM) on endotoxin-induced bacterial translocation, cecal population levels, and ileal histology in protein deficient mice. We administered NNM parenterally because cellular utilization of nucleosides and nucleotides is more efficient as compared to the enteral route (Savaiano et al. 1980; Yamamoto et al. 1993).

\section{Materials and Methods}

\section{Animals and diets}

Conventional ICR (CD-1) that were free of specific pathogens were obtained from Kyudo (Kumamoto) and used for the experiment. Weight-matched (25 to $27 \mathrm{~g}) 8$ weeks old female mice with a stable indigenous GI microflora were kept in 
a constant temperature $\left(25 \pm 2^{\circ} \mathrm{C}\right.$ ) and humidity (50 to $70 \%$ ) room with a $12 \mathrm{hr}$ light period from $08: 00$ to 20:00. The mice were kept for 1 week before the onset of the experiment to acclimatize to our laboratory conditions. During this period, the mice received normal stock (chow) diet. The mice were randomized into 3 groups of 16 animals each and maintained daily throughout a 14-day period on the following diets: Group A (control) mice were fed $20 \%$ nucleic acid-free casein diet (NFD), whereas Groups B and C mice were given a protein-free diet (PFD). The composition of the NFD was the same as shown previously (Adjei et al. 1993) whiles the PFD contained 5\% mineral mixture, $1 \%$ vitamin mixture, $5 \%$ corn oil, $2 \%$ cellulose, and $87 \%$ carbohydrate ( $\alpha$-starch: sucrose, $2: 1$ ). This diet meets the requirements of the "Guide for the Care and Use of Laboratory Animals" and has been used as a standard PFD in our laboratory. In addition, the mice in Groups A and B were administered $0.35 \mathrm{ml}$ saline, whiles Group C mice were administered NNM IP daily throughout the experiment. The NNM (Otsuka Pharmaceutical Factory Inc., Tokushima) is a mixture of nucleosides and nucleotide that was developed to compensate for a decrease in the intrinsic pool of purines and pyrimidines because of increased enzyme activity involve in salvage under various pathologic conditions (Ogoshi et al. 1988). It consisted of inosine $0.8 \mathrm{wt} / \mathrm{vol} \%$, guanosine monophosphate $1.22 \mathrm{wt} / \mathrm{vol} \%$, cytidine $0.73 \mathrm{wt} /$ $\mathrm{vol} \%$, uridine $0.55 \mathrm{wt} / \mathrm{vol} \%$, and thymidine $0.18 \mathrm{wt} / \mathrm{vol} \%$ at a molar ratio of 4 : $4: 4: 3: 1$, respectively. Animals in both groups received food and water ad libitum. From 10 to 11 a.m. every morning, the animals were weighed and food and water were renewed.

\section{Endotoxin}

Lipopolysaccharide (LPS) from Escherichia coli 026: B6 (Wako Chemical Co., Tokyo) was dissolved in a pyrogen-free saline to a final concentration of 50 $\mu \mathrm{g} / 500 \mu \mathrm{l}$. On the 14 th day, mice in each dietary group were administered IP LPS $(50 \mu \mathrm{g} / 500 \mu \mathrm{l})$ and killed by cervical dislocation $48 \mathrm{hr}$ later. We used $50 \mu \mathrm{g}$ LPS because preliminary experiments showed that this dose and timing did not cause death, yet resulted in bacterial translocation in $100 \%$ of the injected mice (data not shown). LPS was used because it has been shown that protein malnutrition or depletion alone do not induce translocation (Deitch et al. 1987).

\section{Bacterial translocation}

Mice were killed by cervical dislocation and the abdomen was swabbed with isodine and later with $70 \%$ alcohol. The skin and peritoneum of the abdomen were opened with sterile instruments, and the exposed viscera were swabbed with cotton-tipped applicator sticks that was cultured in sterile brain heart infusion broth (BHI) to detect any accidental bacterial contamination. The mesenteric lymph node, spleen, liver, and cecum were aseptically removed, weighed and each was placed in tubes containing $3 \mathrm{ml}$ of sterile BHI. The organs were homogen- 
ized with Teflon grinders. After preparations of 10-fold serial dilutions, $100 \mu 1$ aliquots of the homogenate were plated onto polymyxin B nalidixic acid agar for the detection of aerobic and facultative gram-positive bacteria, and onto MacConkey's agar plates for the detection of aerobic and facultative gram-negative bacteria. The plates were incubated at $37^{\circ} \mathrm{C}$ for $24 \mathrm{hr}$; and the bacteria were enumerated as the viable $\log 10$ per tissue. Tissues were considered to be "positive" if greater than 100 colony forming units (CFU)/tissue was found. Representative colonies on both agar plates were identified by using standard microbiologic procedures.

\section{Histologic analysis}

Samples of the distal ileum in each dietary group were removed for histologic analysis. Tissues for light microscopy were fixed in $37-40 \%$ phosphate-buffered formalin (37-49\% formaldehyde $10 \mathrm{ml}$; sodium phosphate monobasic $1.86 \mathrm{~g}$; sodium hydroxide $0.42 \mathrm{~g}$; distilled water $90 \mathrm{ml}$ ) at room temperature overnight. The tissues were sliced into $4-6 \mathrm{~mm}$ pieces, dehydrated in ethanol, embedded in paraffin wax, sectioned and stained with hematoxylin and eosin. The sections were examined and photographed with the use of an Olympus research microscope (Olympus Kogyo Co., Tokyo). The measurement of villus height, crypt depth, and wall thickness were measured in properly oriented crypt-villus units per segment using a calibrated micrometer.

\section{Statistical analysis}

Data were analyzed by Fisher's exact-test and the Duncan multiple range $t$-test. Values less than 0.05 were considered significant.

\section{RESUlts}

After feeding 14 days with PFD, the mice in Groups B and C lost about 25\% of their original body weight. No animal died during the period of protein depletion; however, $48 \mathrm{hr}$ after LPS injection, $4(25 \%)$ of the mice in Group B died. No death was observed in Groups A and C.

Forty-eight hours after IP administration of LPS, the incidence of bacterial translocation in the MLN (62\%) of Group C mice differed significantly in comparison to the Group B $(100 \%)$ mice $(p<0.01)$. Although the incidences of translocation in the spleen $(68 \%)$, liver $(62 \%)$ of the surviving mice in Group $\mathrm{C}$ tended to be lower than the rates in Group B (spleen 83\%; liver 83\%), there was no difference statistically (Table 1). There was no translocation in Group A mice.

Table 2 shows the morphometric analysis of the distal ileum in each dietary group. The villus height, crypt depth, and wall thickness in Group B ( $3.92 \pm 0.74$; $0.99 \pm 0.19 ; 0.29 \pm 0.02)$, respectively, were significantly lower in comparison with Groups A $(6.99 \pm 0.35 ; 1.54 \pm 0.07 ; 0.40 \pm 0.05)$ and $\mathrm{C} \quad(5.50 \pm 0.47 ; 1.20 \pm 0.20$; $0.35 \pm 0.04)(p<0.05)$. The basal gland counts in Group C $(143 \pm 5)$ differed 
TABLE 1. Endotoxin-induced bacterial translocation from the gastrointestinal tract in mice ${ }^{1}$

\begin{tabular}{lcccc}
\hline \multirow{2}{*}{$\begin{array}{l}\text { Experimental } \\
\text { group }\end{array}$} & & \multicolumn{2}{c}{ Incidence of bacteria translocation $^{2}$} \\
\cline { 3 - 5 } & $\mathrm{n}$ & $\mathrm{MLN}^{3}$ & Spleen & Liver \\
\hline Group A & 16 & $0 \% \%^{\mathrm{a}, 4}$ & $0 \% \%^{\mathrm{a}}$ & $0 \% \%^{\mathrm{a}}$ \\
Group B & 12 & $100 \% \%^{\mathrm{b}}$ & $83 \% \%^{\mathrm{b}}$ & $83 \%{ }^{\mathrm{b}}$ \\
Group C & 16 & $62 \%{ }^{\mathrm{c}}$ & $68 \%{ }^{\mathrm{b}}$ & $62 \% \mathrm{o}^{\mathrm{b}}$ \\
\hline
\end{tabular}

${ }^{1}$ Mice were fed $20 \%$ casein diet (Group A), and protein-free $\operatorname{diet}$ (Group B and C). The mice in Group A and B were intraperioneally administered $0.35 \mathrm{ml}$ saline whereas mice in Group $\mathrm{C}$ were administered nucleoside-nucleotide mixture for 14 days.

${ }^{2}$ Endotoxin administered ip $(50 \mu \mathrm{g})$ and mice killed $48 \mathrm{hr}$ later. $\%$ translocation detemined by dividing number of mice with bacteria in the irrespective organs by total number of animals tested.

${ }^{3}$ Translocating bacteria were identified as $E$. coli, $P$. areuginosa, M. morgani, and Enterococcus sp.

${ }^{4}$ Different letters in a column indicate significant difference by Fisher's exact test, $(p<0.05)$.

TABLE 2. Effect of nucleoside-nucleotide mixture on the histology of the mouse ileum ${ }^{1}$

\begin{tabular}{lccc}
\hline & $\begin{array}{c}\text { Group A } \\
(n=16)\end{array}$ & $\begin{array}{c}\text { Group B } \\
(n=12)\end{array}$ & $\begin{array}{c}\text { Group C } \\
(n=16)\end{array}$ \\
\hline Villus height & $6.99 \pm 0.35^{\mathrm{a}}$ & $3.92 \pm 0.74^{\mathrm{b}}$ & $5.50 \pm 0.47^{\mathrm{c}}$ \\
Crypt depth & $1.54 \pm 0.07^{\mathrm{a}}$ & $0.99 \pm 0.19^{\mathrm{b}}$ & $1.20 \pm 0.20^{\mathrm{c}}$ \\
Wall thickness & $0.40 \pm 0.05^{\mathrm{a}}$ & $0.29 \pm 0.02^{\mathrm{b}}$ & $0.35 \pm 0.04^{\mathrm{a}}$ \\
Basal gland counts & $139 \pm 5^{\mathrm{a}}$ & $129 \pm 5^{\mathrm{a}, \mathrm{c}}$ & $143 \pm 5^{\mathrm{c}}$ \\
\hline
\end{tabular}

${ }^{1}$ Villus height, crypt depth, and wall thickness were determined by measuring well-oriented villi, crypt, and wall thickness per sample. Values are expressed as mean \pm s.E. in $\mathrm{mm} \times 10^{-1}$.

Mice were fed $20 \%$ casein diet (Group A), and protein-free diet (Groups B and C). The mice in Groups A and B were intraperitoneally administered $0.35 \mathrm{ml}$ saline whereas mice in Group C were administered nucleosides-nucleotide mixture for 14 days.

Values with different superscripts differ $(p<0.05$, Duncan's multiple $t$-test).

significantly compared to Group B $(129 \pm 5)$, but tended to be higher than Group A $(139 \pm 5)$ without significant difference.

Fig. 1 confirms the atrophic changes of the distal ileum in Group B. Histologically, the density and the height of the intestinal villi were narrower and shorter than in Groups A and C. Villus edema was evident with separation of the epithelium from the underlying tissues and breaks in the epithelial barrier was observed. Interestingly, the histologic changes observed in mice fed PFD supplemented with NNM (Group C) was comparable to the mice fed $20 \%$ casein 
A.A. Adjei et al.
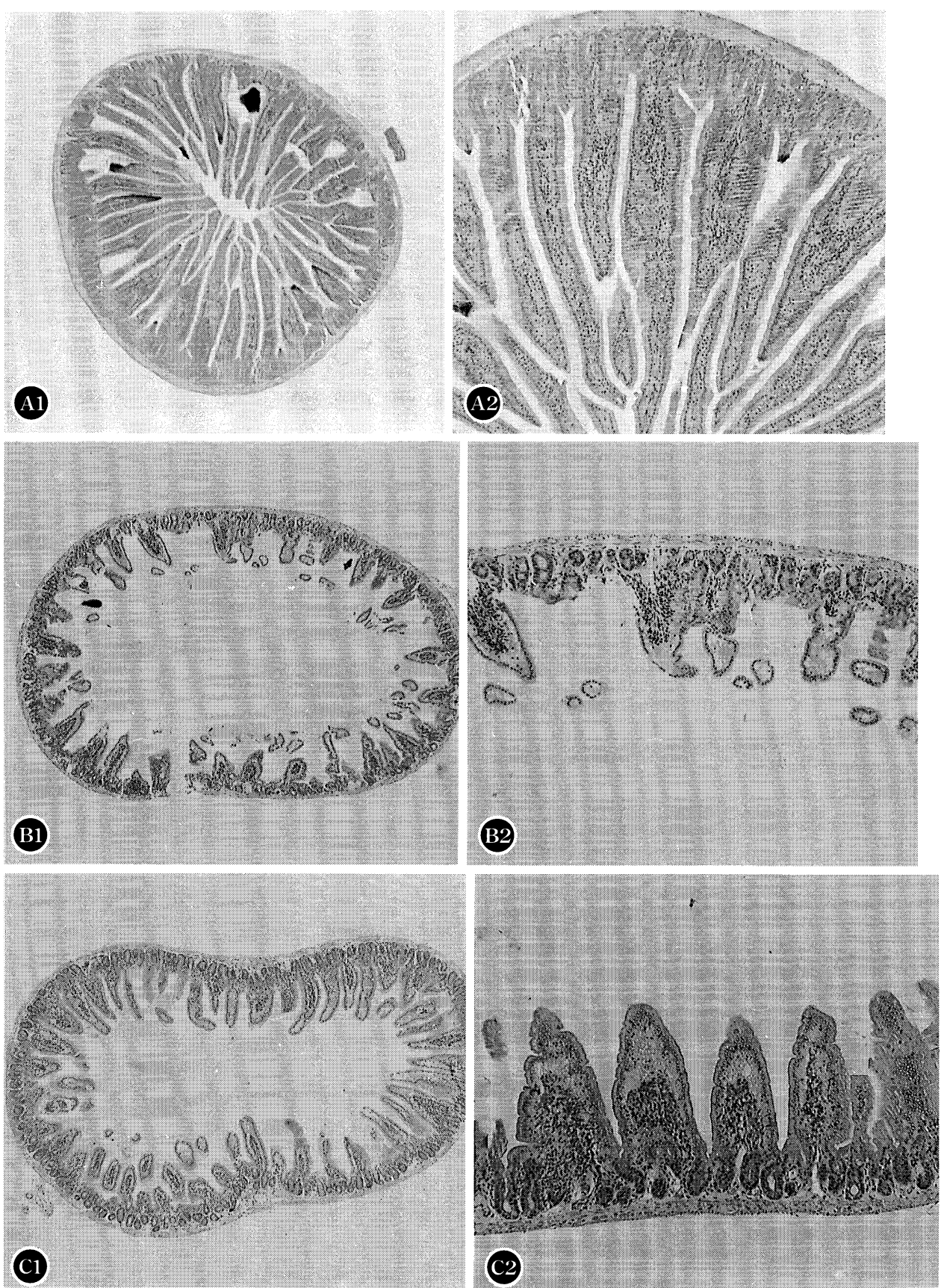

Fig. 1. 
TABLE 3. Quantification of bacterial translocation of aerobic and facultative gramnegative and grampositive enterics in mice ${ }^{1}$

\begin{tabular}{lllll}
\hline & \multicolumn{1}{c}{$\begin{array}{c}\text { Group A } \\
(n=16)\end{array}$} & $\begin{array}{c}\text { Group B } \\
(n=12)\end{array}$ & $\begin{array}{c}\text { Group C } \\
(n=16)\end{array}$ \\
\hline Gram-negative aerobes & & & & \\
& MLN $^{2}$ & $0^{\mathrm{a}, 3}$ & $4.99 \pm 1.75^{\mathrm{b}}$ & $3.78 \pm 1.10^{\mathrm{c}}$ \\
& Spleen & $0^{\mathrm{a}}$ & $5.22 \pm 1.74^{\mathrm{b}}$ & $4.11 \pm 1.34^{\mathrm{c}}$ \\
& Liver & $0^{\mathrm{a}}$ & $5.34 \pm 1.76^{\mathrm{b}}$ & $4.02 \pm 1.33^{\mathrm{b}}$ \\
& Cecum & $5.77 \pm 1.07$ & $6.25 \pm 2.22$ & $5.99 \pm 1.82$ \\
Gram-positive aerobes & & & & \\
& MLN & $0^{\mathrm{a}}$ & $4.98 \pm 1.75^{\mathrm{b}}$ & $4.23 \pm 1.31^{\mathrm{b}}$ \\
& Spleen & $0^{\mathrm{a}}$ & $5.02 \pm 1.73^{\mathrm{b}}$ & $4.58 \pm 1.49^{\mathrm{b}}$ \\
& Liver & $0^{\mathrm{a}}$ & $5.04 \pm 1.75^{\mathrm{b}}$ & $4.72 \pm 1.52^{\mathrm{b}}$ \\
& Cecum & $5.02 \pm 0.97$ & $6.19 \pm 2.11$ & $5.81 \pm 1.84$ \\
\hline
\end{tabular}

${ }^{1}$ Mice were fed $20 \%$ casein diet (Group A), or protein-free diet (Groups B and C). The mice in Groups A and B were intraperitoneally administered $0.35 \mathrm{ml}$ saline, whereas mice in Group $\mathrm{C}$ were administered nucleoside-nucleotide mixture for 14 days. Values are expressed as mean $\log \pm$ S.E.

${ }^{2}$ Translocating bacteria were idenified as $E$. coli, $P$. aeruginosa, M. morgani, and Enterococcus sp.

${ }^{3}$ Different letters indicate significant difference by Fisher's exact test, $(p<0.05)$.

(control, Group A) diet.

The colony forming units (CFU) of viable aerobic and facultative gramnegative enterics recovered from the MLN and spleen of the surviving mice in the Group B were significantly higher as compared to the mice in Group C (Table 3, $p<0.05)$. Although the CFU of gram-positive enterics tended to be lower in Group C in comparison with Group B, the values were not different statistically (Table 3). Although NNM decreased the incidence of bacterial translocation and the number of CFU recovered in the MLN and spleen, it could not reduce the number of cecal poulation levels in both groups of surviving mice (Table 3) suggesting that bacterial overgrowth was not responsible for these findings.

Fig. 1. Terminal ileum from a control (20\% casein) mouse killed $48 \mathrm{hr}$ after an intraperitoneal endotoxin $(50 \mu \mathrm{g})$ administration showing normal mucosal architecture $(A, \times 200)$. Terminal ileum from a protein-free diet fed mouse intraperitoneally administered saline and killed $48 \mathrm{hr}$ after an intraperitoneal endotoxin $(50 \mu \mathrm{g})$ administration. Atrophy of the intestinal mucosa and wall are evident. The villous has been eroded and shortened down to the level of the crypts, with a marked decrease in the thickness of the intestinal wall $(B, \times 200)$. Terminal ileum from a protein-free diet fed mouse intraperitoneally administered nucleic acid components and killed $48 \mathrm{hr}$ after an intraperitoneal endotoxin $(50 \mu \mathrm{g})$ administration. Trophic changes of the intestinal mucosa and wall are comparable to that of $\mathrm{A}$. The villous height, crypt depth, and wall thickness are well developed and remain intact $(\mathrm{C}, \times 200)$. 


\section{DiscUssion}

The results of our study suggest that NNM can modulate gut structure and function since the villus height, crypt depth, and total wall thickness in Group C were much superior in comparison with those in Group B (Fig. 1, Table 2). The healthy gut was characterized by intact villus tips, normal cellularity resulting in a reduced incidence of bacterial translocation to the MLN in the group administered NNM intraperitoneally (Table 1). The profound improvement in the gut architecture was certified by the significant reduction of CFU of aerobic and facultative gram-negative enterics recovered in the MLN and spleen of the surviving mice in the NNM (Group C) group as compared to the mice in Group A. As demonstrated by light microscopy (Fig. 1), protein deficiency in combination with endotoxin, caused profound alterations in the villus, separation of the epithelium from the basal lamina, and produced gross breaks in the epithelial barrier in some areas of the ileum in Group B mice in comparison with those in Group C suggesting that endogenous supply of NNM was inadequate to maintain gut integrity in certain clinical conditions, whereas exogenous supply of NNM resulted in ileum mucosal repair, integrity and function. Additionally, Group B mice were more susceptible to the lethal effects of endotoxin as compared to the mice in Group C. Based on these results we can speculate that NNM may be effective in inhibiting bacterial translocation and in improving morphologic changes in the GI tract associated with protein deficiency and endotoxemia.

Growing evidences suggest that nucleosides and nucleotides may be a "conditionally semi-essential nutrient" during repair of the injured gut mucosa or during periods of rapid growth and development. Iijima and associates (1993) demonstrated that supplementation of total parenteral nutrition with NNM prevented the intestinal mucosal atrophic changes in rats and the effect was more evident in the ileum as compared to the non-supplemented group. It has been reported that dietary nucleotides appeared to be the modulators of intestinal development after chronic diarrhea in lactose-induced malnourished rats (Nunez et al. 1990), suggestive that dietary nucleotides may have an important implications in the growth, maturation, reparation of the small intestine during injury. Uauy and colleagues (1990) also reported that diets free of nucleosides and nitrogenous bases may have an adverse effects on the gut. Dietary nucleotides have also been shown to serve as precursors units of DNA and RNA especially under a relatively low intake of proteins and could have an important role in gut intestinal development and maturation (LeLeiko et al. 1983). From these studies we can infer that nucleic acid synthesis in tissues of rapid growth (for example the gut) via the salvage pathway is not sufficient for development and maturation; and especially in those intestinal diseases in which the mucosa is damaged or altered, nucleosides and nucleotides may be semi-essential.

The exact mechanism(s) by which NNM inhibits bacterial translocation 
cannot be discerned from our study. However, since protein malnutrition and endotoxemia induces a variety of immunosuppressive effects involving both specific and non-specific host defenses, one major mechanism by which protein malnutrition and endotoxemia promotes bacterial translocation is by impairing host immune defenses. From our studies it is likely that NNM enhanced the immune defense system of the Group $\mathrm{C}$ mice resulting in a higher survival through the liberation of secondary mediators. This probability is supported by observations that nucleotides elevates interleukin-2 (IL-2) levels. Kulkarni and colleagues (1989) reported that increased production of IL-2 effected the activation and function of T-helper cells leading to active macrophages efficient in their phagocyte and antigen processing functions - a vital stage in the immune response pathway. It is also possible that the higher mortality and the increased incidence of translocation observed in the saline group (Group B) could be indirectly attributed to a T-cell deficit or impaired bactericidal activity of splenic macrophages (Pizzini et al. 1990). Based on the evidence presented in this study and from the reports of other investigators, it seems that exogenous NNM as the sole nutrient may help meet the increased demand for nucleosides and nucleotides required during repair of the injured GI tract. Since NNM alone will prevent some of the morphologic and immunologic changes secondary to protein malnutrition and endotoxemia, this substrate combined with other essential substrates should result in an even more protective or reparative effect. Further studies in other animal models are necessary to confirm and establish the beneficial role(s) of nucleosides and nucleotides.

\section{References}

1) Adjei, A.A., Takamine, F., Yokoyama, H., Shiokawa, K., Matsumoto, Y., Asato, L., Shinjo, S., Imamura, T. \& Yamamoto, S. (1993) The effects of oral RNA and intraperitoneal nucleoside-nucleotide administration on methicillin-resistant Staphylococcus aureus infection in mice. J. Parenter. Enteral Nutr., 17, 148-152.

2) Berg, R.D. \& Garlington, A.W. (1979) Translocation of certain indigenous bacteria from the gastrointestinal tract to the mesenteric lymph nodes and other organs in a gnotobiotic mouse model. Infect. Immun., 23, 403.

3) Deitch, E.A., Winterton, J., Li, M. \& Berg, R.D. (1987) The gut as a portal of entry for bacteremia: The role of protein malnutrition. Ann. Surg., 205, 681-692.

4) Garre, M.A., Boles, J.M. \& Youinou, P.Y. (1987) Current concepts in immune derangement due to undernutrition. J. Parenter. Enteral Nutr., 11, 309.

5) Iijima, S., Tsujinaka, T., Kido, Y., Hayashida, Y., Ishida, H., Homma, T., Yokoyama, H. \& Mori, T. (1993) Intravenous administration of nucleosides and a nucleotide mixture diminshes intestinal mucosal atrophy by total parenteral nutrition. $J$. Parenter. Enteral Nutr., 17, 265-270.

6) Kulkarni, A.D., Fanslow, W.C., Higley, H., Pizzini, R., Rudolph, F.B. \& Van Buren, C.T. (1989) Expression of immune cell surface markers in vivo and immune competence in mice by dietary nucleotides. Transplant. Proc., 21, 121-124.

7) LeLeiko, N.S., Bronstein, A.D. \& Baliga, S. (1983) De novo purine nucleotide synthesis in the rat small and large intestine. J. Pediatr. Gastroenterol. Nutr., 2, 313317. 
8) Nunez, M.C., Ayudarte, M.V., Morales, M., Suarez, M.D. \& Gill, A. (1990) Effect of dietary nucleotides on intestinal repair in rats with experimental chronic diarrhea. $J$. Parenter. Enteral Nutr., 14, 598-604.

9) Ogoshi, S., Iwasa, M. \& Kitagawa, S. (1988) Effect of total parenteral nutrition with nucleoside and nucleotide mixture on D-galactosamine-induced liver injury in rats. $J$. Parenter. Enteral Nutr., 12, 53-57.

10) Pizzini, R.P., Kumar, S., Kulkarni, A.D., Rudolph, F.B. \& Van Buren, C.T. (1990) Dietary nucleotides reverse malnutrition and starvation-induced immunosuppression. Arch. Surg., 125, 86-90.

11) Saadia, R., Schein, M., Macfarlane, C. \& Boffard, K.D. (1990) Gut barrier function and the surgeon. Br. J. Surg., 77, 487-492.

12) Savaiano, D.A., Ho, C.Y., Chu, V. \& Clifford, A.D. (1980) Metabolism of orally and intravenously administered purines in rats. J. Nutr., 110, 1793-1804.

13) Uauy, R., Stringel, G., Thomas, R. \& Quan, R. (1990) Effect of dietary nucleosides on growth and maturation of the development of the gut in the rat. J. Pediatr. Gastroenterol. Nutr., 10, 497-503.

14) Wells, C.L., Maddaus, M.A. \& Simmons, R.L. (1988) Prosposed mechanisms for the translocation of intestinal bacteria. Rev. Infect. Dis., 10, 958-979.

15) Wilmore, D.W., Smith, R.J., O'Dwyer, S.T., Jacobs, D.O., Ziegler, T.R. \& Wang, X.D. (1988) The gut: A central organ after surgical stress. Surgery, 104, 917-923.

16) Yamamoto, S., Adjei, A.A., Matsumoto, Y., Takamine, F. \& Suzuki, I. (1994) Comparative effects of orally and intraperitoneally administered RNA and nucleic acid components on response to methicillin-resistant Staphylococcus aureus infection in mice. J. Nutr. Immunol., 2, 17-28. 